\title{
In Situ Investigation of Microstructure Evolution during Solidification of Mg10CaxGd $(x=5,10,20)$ Alloys
}

\author{
C.L. Mendis ${ }^{a, *}$, D. TOlnai ${ }^{a}$, A. StARK $^{b}$, N. Schell ${ }^{c}$, K.U. KAiner ${ }^{a}$ And N. Hort ${ }^{a}$ \\ ${ }^{a}$ Magnesium Innovation Centre, Helmholtz-Zentrum Geesthacht, Max Planck Str. 1, Geesthacht D-21502, Germany \\ ${ }^{b}$ Department of Metal Physics, Helmholtz-Zentrum Geesthacht, Max Planck Str. 1, Geesthacht D-21502, Germany \\ ${ }^{c}$ Structural Research on New Materials, Helmholtz-Zentrum Geesthacht, Outstation at DESY, \\ Notkestr. 85, Hamburg D-22761, Germany
}

\begin{abstract}
$\mathrm{Mg}-\mathrm{Ca}-\mathrm{Gd}$ based alloys are investigated as a potential alloy for degradable biomaterials with some promising results. In this investigation the $\operatorname{Mg} 10 \mathrm{Ca} x \mathrm{Gd}(x=5,10,20)$ were investigated with synchrotron radiation X-ray diffraction during solidification to follow the phase evolution at two different cooling rates at 5 and $50 \mathrm{~K} \mathrm{~min}^{-1}$. All three alloys show formation of $\alpha$ - Mg followed by $\mathrm{Mg}_{2} \mathrm{Ca}$ phase, while only Mg10Ca20Gd alloy contained $\mathrm{Mg}_{5} \mathrm{Gd}$ phase during solidification. During cooling $\alpha-\mathrm{Mg}$ was first observed between 628 and $632{ }^{\circ} \mathrm{C}$ at a cooling rate of $5 \mathrm{~K} \mathrm{~min}^{-1}$ while this decreased to $620-628^{\circ} \mathrm{C}$ with the increase in cooling rate to $50 \mathrm{~K} \mathrm{~min}{ }^{-1}$. The change in cooling rate from 5 to $50 \mathrm{~K} \mathrm{~min}^{-1}$ did not change the types of intermetallic phases observed but resulted in suppressing temperatures at which the intermetallic phases were first detected.
\end{abstract}

DOI: 10.12693 /APhysPolA.128.606

PACS: $81.05 . \mathrm{Bx}, 81.30 . \mathrm{Fb}$

\section{Introduction}

Magnesium alloys have attracted significant interest in the last two decades due to their relatively low density compared with other structural alloys in applications where light weight is of importance. Recently the interest in magnesium alloys extends to include degradable biological implants due to their biocompatibility and degradation in biological environments. $\mathrm{Mg}-\mathrm{RE}(\mathrm{RE}=$ rare earth) based, especially $\mathrm{Mg}-\mathrm{Gd}$ based [1], alloys have shown to form the basis of a class of high strength and creep resistant alloys that have been developed to be used in structural settings where elevated temperature stability is of importance as well as high strength at room temperatures. $\mathrm{Mg}-\mathrm{Gd}[1]$ and $\mathrm{Mg}-\mathrm{Gd}-\mathrm{Dy}$ [2] alloys are also studied extensively due to the low degradation rates observed in in vitro investigations for degradable biological implants.

A large amount of RE additions is required for appreciable strengthening increments through either formation of intermetallic particles along the grain boundaries or through formation of a high density of precipitates during isothermal ageing heat treatments. For $\mathrm{Mg}-\mathrm{Gd}$ alloys a minimum of $10 \mathrm{wt} \%$ of $\mathrm{Gd}$ is required for appreciable increment in strengths through precipitation hardening [1]. More than $15 \mathrm{wt} \% \mathrm{Gd}$ is required to form intermetallic particles along the grain boundaries to provide strengthening due to the presence of intermetallic particles in the cast alloys [1]. The high content of Gd required and the prohibitive cost of $\mathrm{RE}$ additions results in $\mathrm{Mg}-\mathrm{Gd}$ alloys not attractive for all but specialist structural

* corresponding author; e-mail: Chamini.mendis@hzg.de applications. Thus, there is continued interest in developing alloys that retain the attractive properties of Mg-(10-20)Gd alloys but with significantly lower Gd contents. The addition of $\mathrm{Zn} \mathrm{[3]} \mathrm{and} \mathrm{Al}$ [4] to the $\mathrm{Mg}-\mathrm{Gd}$ system has shown to produce a high density of long period stacking ordered (LPSO) phases with relatively lower concentrations of $\mathrm{Gd}$ while retaining higher strengths. It has been also shown that the addition of $\mathrm{Zn}$ to alloys containing relatively lower concentrations $(\approx 6 \mathrm{wt} \%)$ Gd show remarkable increments in precipitation hardening [5]. Similar observations are made with the addition of silver to $\mathrm{Mg}-6 \mathrm{Gd}$ alloy [6].

$\mathrm{Ca}$ has been shown to behave in a manner similar to Gd in magnesium alloys with similar modifications to the texture of magnesium alloys [7]. However, Ca has a much lower solid solubility in magnesium and forms intermetallic particles along the grain boundaries [8]. The effect of $\mathrm{Ca}$ addition to $\mathrm{Mg}-\mathrm{Gd}$ alloys on the microstructural evolution during casting has not been investigated. Fei et al. [9] investigated a range of alloys using X-ray diffraction (XRD) electron probe micro analysis (EPMA) and scanning electron microscopy (SEM) to determine the magnesium rich end of the ternary phase diagram at $400^{\circ} \mathrm{C}$. In this study a ternary phase with a crystal structure and lattice parameters similar to $\mathrm{Mg}_{41} \mathrm{Ce}_{5}$ [9] phase, denoted $\mathrm{T}$ phase, was detected using XRD and SEM. However, the exact nature of this ternary phase is yet to be elucidated, He et al. [10] investigating the effect of $0.4-0.6 \mathrm{wt} \% \mathrm{Ca}$ addition to a Mg10Gd3Y0.4Zr (wt\%) found that new cuboidal type precipitates were found at grain boundaries containing $\mathrm{Gd}, \mathrm{Y}$ and $\mathrm{Ca}$. In $\mathrm{Mg} 3.8 \mathrm{Zn} 2.2 \mathrm{Ca}$ (wt\%) alloys addition of $\mathrm{Gd}$ did not affect the microstructure, especially the solid-state precipitation, during heat treatments, but had a slight influence on the mechanical properties. 
The work to date shows that the addition of $\mathrm{Ca}$ to $\mathrm{Mg}-$ Gd alloys may result in improving mechanical properties and strengthening through modifying intermetallic particles that form during solidification. However, there is a lack of information on changing the ratio between $\mathrm{Ca}$ and Gd on the microstructure evolution during solidification. In this contribution we report the findings from an in situ synchrotron radiation diffraction solidification experiment coupled with electron microscopy on the microstructure evolution in $\mathrm{Mg}-\mathrm{Ca}-\mathrm{Gd}$ alloys. The change in the $\mathrm{Ca}: \mathrm{Gd}$ ratio and the cooling rates will provide information valuable for the development of phase diagrams as well as contribute to the design of $\mathrm{Mg}-\mathrm{Ca}-\mathrm{Gd}$ based alloys.

\section{Experimental procedure}

Pure Mg (99.99\% Hydro Magnesium), was melted in a mild steel crucible and $\mathrm{Mg}-23 \mathrm{Gd}$ master alloy (from State Key Laboratory of Rare Earth Resource Utilization, Changchun Institute of Applied Chemistry, Chinese Academy of Sciences) and pure Ca (99\% Alfa Aesar) was added to the melt at $720^{\circ} \mathrm{C}$. The melt was held at about $750^{\circ} \mathrm{C}$ for 15 min to incorporate the alloying additions uniformly through the melt and stirred. The alloys were then cast into a hardened steel finger mould held at $350{ }^{\circ} \mathrm{C}$. The chemical composition of the samples was analysed and both the nominal and the actual composition values are listed in Table I. All compositions are in $\mathrm{wt} \%$.

TABLE I

Actual compositions of the alloys investigated.

\begin{tabular}{c|c|c|c}
\hline \hline \multirow{2}{*}{ Alloy } & \multicolumn{3}{|c}{ Actual composition [wt\%] } \\
\cline { 2 - 4 } & $\mathrm{Ca}$ & $\mathrm{Gd}$ & $\mathrm{Mg}$ \\
\hline Mg10Ca5Gd & 8 & 5 & bal \\
Mg10Ca10Gd & 8 & 9.5 & bal \\
Mg10Ca20Gd & 8 & 21 & bal
\end{tabular}

The metallographic samples were prepared by grinding samples with $\mathrm{SiC}$ paper to 2500 grit finish and then polishing in $3 \mu \mathrm{m}$ diamond suspension and a mixture of $1 \mu \mathrm{m}$ diamond and OPS suspension. Scanning electron microscopy, in backscattered electron (SEM-BSE) mode, investigations were conducted with a TESCAN SEM equipped with an EDAX energy dispersive X-ray (EDX) spectrometer. The phase evolution expected for each of these alloys and the temperatures at which the expected phases will appear are calculated with Pandat Thermodynamic software and PanMg 8 database using the Scheil solidification model.

The synchrotron radiation diffraction experiments during solidification of the alloys were conducted at the PETRA III P07 High Energy Materials Science (HEMS) Beamline of Helmholtz Zentrum Geesthacht (HZG) at the Deutsches Elektronen-Synchroton (DESY). The measurements were performed in the chamber of a Bähr 805 dilatometer in Ar flow. The beam energy used in this investigation was set at $100 \mathrm{keV}$ which corresponds to a wavelength of $0.0124 \mathrm{~nm}$. The dilatometer has been modified for in situ synchrotron radiation measurements, there are two windows on the sides covered by Kapton foil, which is transparent for the X-ray beam, and the induction coil opened in the middle so that the beam passes through only the sample and the crucible. During the test the sample was contained in graphite crucibles closed with titanium lids with a type $\mathrm{S}$ thermocouple controlling the measurement welded onto the surface of the lid. Samples of the investigated alloys were heated to $750^{\circ} \mathrm{C}$ at $40 \mathrm{~K} \mathrm{~min}^{-1}$ held at $750^{\circ} \mathrm{C}$ for $10 \mathrm{~min}$. The samples were then cooled at $5 \mathrm{~K} \mathrm{~min}^{-1}$ or $50 \mathrm{~K} \mathrm{~min}^{-1}$ to $200^{\circ} \mathrm{C}$ and then air cooled to follow the microstructure evolution during cooling from the melt. The $2 \mathrm{D}$ diffraction patterns were recorded with an acquisition time of $3.5 \mathrm{~s}(\approx 1 \mathrm{~K})$ with a Perkin Elmer XRD 1621 Flat Panel detector with a pixel size of $200 \times 200 \mu \mathrm{m}^{2}$ and were azimuthally integrated to obtain X-ray line profiles. The information on the intermetallic phases were obtained from the Pearson Crystal Structure Database [11], the $d$-spacing and $2 \theta$ angles were calculated using CaRIn Crystallography $3.1^{\mathrm{TM}}$ software.

\section{Results}

The Scheil solidification calculations showing calculated transformation temperatures and phases expected and their volume fractions are shown in Table II. The addition of Gd to Mg10Ca alloy changes only the volume fraction of the expected phases, the types of phases observed did not change. The volume fraction of intermetallic phases also increased with $\mathrm{Gd}$ content with both $\mathrm{Mg}_{2} \mathrm{Ca}$ contents reaching a maximum at $\mathrm{Mg} 10 \mathrm{Ca} 20 \mathrm{Gd}$ alloy where the main phase observed is $\mathrm{Mg}_{2} \mathrm{Ca}$.

TABLE II

Transformation temperatures of $\alpha-\mathrm{Mg}$ and intermetallic phases predicted by the Scheil solidification calculations using Pandat 8 software.

\begin{tabular}{c|c|c|c}
\hline \hline \multirow{2}{*}{ Alloy } & \multicolumn{3}{|c}{$\begin{array}{c}\text { Temperature at which the phase } \\
\text { is detected }\left[{ }^{\circ} \mathrm{C}\right]\end{array}$} \\
\cline { 2 - 4 } & $\alpha-\mathrm{Mg}$ & $\mathrm{Mg} 2 \mathrm{Ca}$ & $\mathrm{Mg} 5 \mathrm{Gd}$ \\
\hline Mg10Ca5Gd & 564 & 513 & 509 \\
Mg10Ca10Gd & 547 & 510 & 509 \\
Mg10Ca20Gd & 541 & 513 & 509
\end{tabular}

TABLE III

Pertinent temperatures for phase evolution observed during solidification studies using in situ HEXRD.

\begin{tabular}{c|c|c|c|c|c|c}
\hline \hline \multirow{2}{*}{ Alloy } & \multicolumn{4}{|c|}{$\begin{array}{c}\text { Transformation temperatures for various } \\
\left.\text { phases at a given cooling rate [ }{ }^{\circ} \mathrm{C}\right]\end{array}$} \\
\cline { 2 - 7 } & \multicolumn{3}{|c|}{$5 \mathrm{~K} \mathrm{~min}^{-1}$} & \multicolumn{3}{c}{$50 \mathrm{~K} \mathrm{~min}{ }^{-1}$} \\
\cline { 2 - 7 } & $\alpha-\mathrm{Mg}$ & $\mathrm{Mg}_{2} \mathrm{Ca}$ & $\mathrm{Mg}_{5} \mathrm{Gd}$ & $\alpha-\mathrm{Mg}^{-1} \mathrm{Mg}_{2} \mathrm{Ca}$ & $\mathrm{Mg}_{5} \mathrm{Gd}$ \\
\hline $\mathrm{Mg} 10 \mathrm{Ca} 5 \mathrm{Gd}$ & 632 & 504 & - & 628 & 450 & - \\
$\mathrm{Mg} 10 \mathrm{Ca} 10 \mathrm{Gd}$ & 625 & 506 & - & 620 & 498 & - \\
$\mathrm{Mg} 10 \mathrm{Ca} 20 \mathrm{Gd}$ & 626 & 515 & 504 & 620 & 446 & 417
\end{tabular}




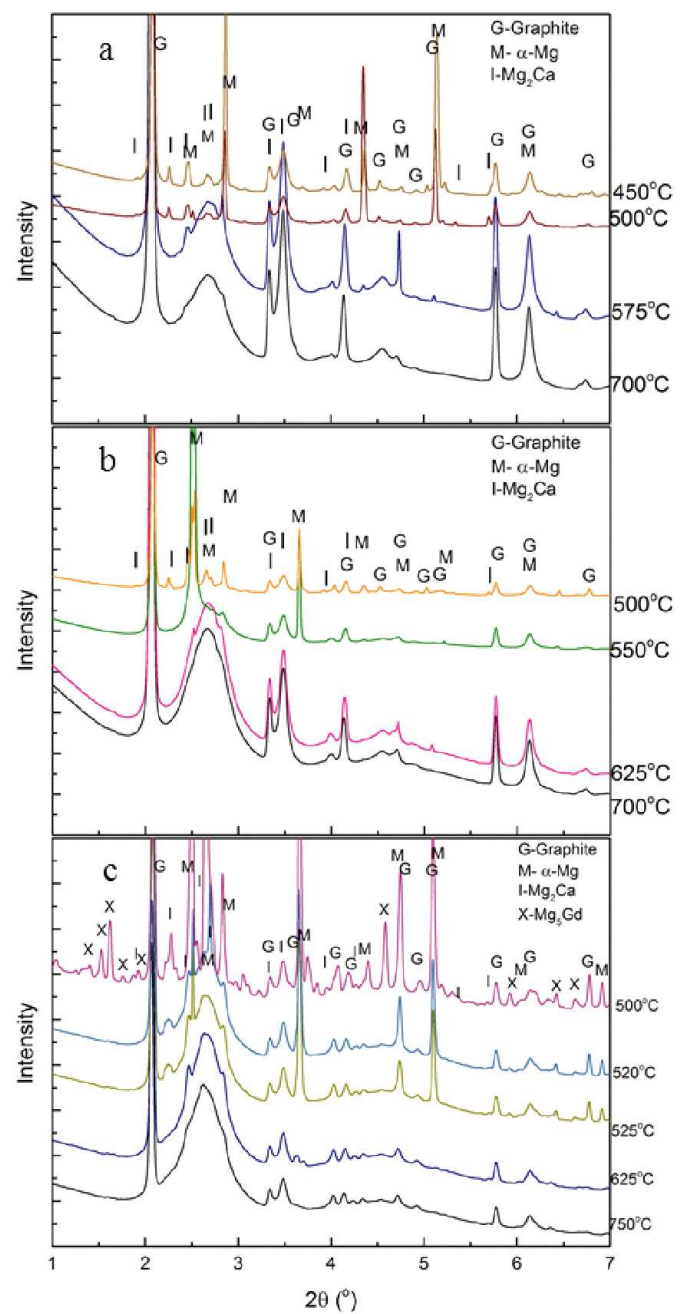

Fig. 1. In situ HEXRD line profiles recorded from (a) Mg10Ca5Gd (b) Mg10Ca10Gd and (c) Mg10Ca20Gd alloys during solidification at a cooling rate of $5 \mathrm{~K} \mathrm{~min}^{-1}$.

The azimuthally integrated high energy X-ray diffraction (HEXRD) line profiles for the $\operatorname{Mg} 10$ Cax $\mathrm{Gd}(x=5$, 10, 20) alloys cooled at $5 \mathrm{~K} \mathrm{~min}^{-1}$ are shown in Fig. 1 and the temperatures at which the phase transformations occur are summarised in Table III. The first phase to solidify in all alloys was $\alpha-\mathrm{Mg}$ followed by $\mathrm{Mg}_{2} \mathrm{Ca}$. $\mathrm{Mg}_{5} \mathrm{Gd}$ phase was only detected in the Mg10Ca20Gd alloy using HEXRD. The $\alpha-\mathrm{Mg}$ started to solidify at $632 \pm 5,625 \pm 5$, and $627 \pm 5^{\circ} \mathrm{C}$ for $\mathrm{Mg} 10 \mathrm{Ca} 5 \mathrm{Gd}$, Mg10Ca10Gd, and Mg10Ca20Gd alloys, respectively. The $\mathrm{Mg}_{2} \mathrm{Ca}$ phase was detected at $504 \pm 5,506 \pm 5$, and $515 \pm 5{ }^{\circ} \mathrm{C}$ for $\mathrm{Mg} 10 \mathrm{Ca} 5 \mathrm{Gd}, \mathrm{Mg} 10 \mathrm{Ca} 10 \mathrm{Gd}$, and Mg10Ca20Gd, respectively, while $\mathrm{Mg}_{5} \mathrm{Gd}$ was detected at $509{ }^{\circ} \mathrm{C}$ in $\mathrm{Mg} 10 \mathrm{Ca} 20 \mathrm{Gd}$ alloy.

The increase in the cooling rate to $50 \mathrm{~K} \mathrm{~min}^{-1}$ did not change the types of intermetallic particles observed in the HEXRD patterns, Fig. 2, and the pertinent transformation temperatures for the phases observed are summarised in Table III. However, the temperatures at which various intermetallic phases formed

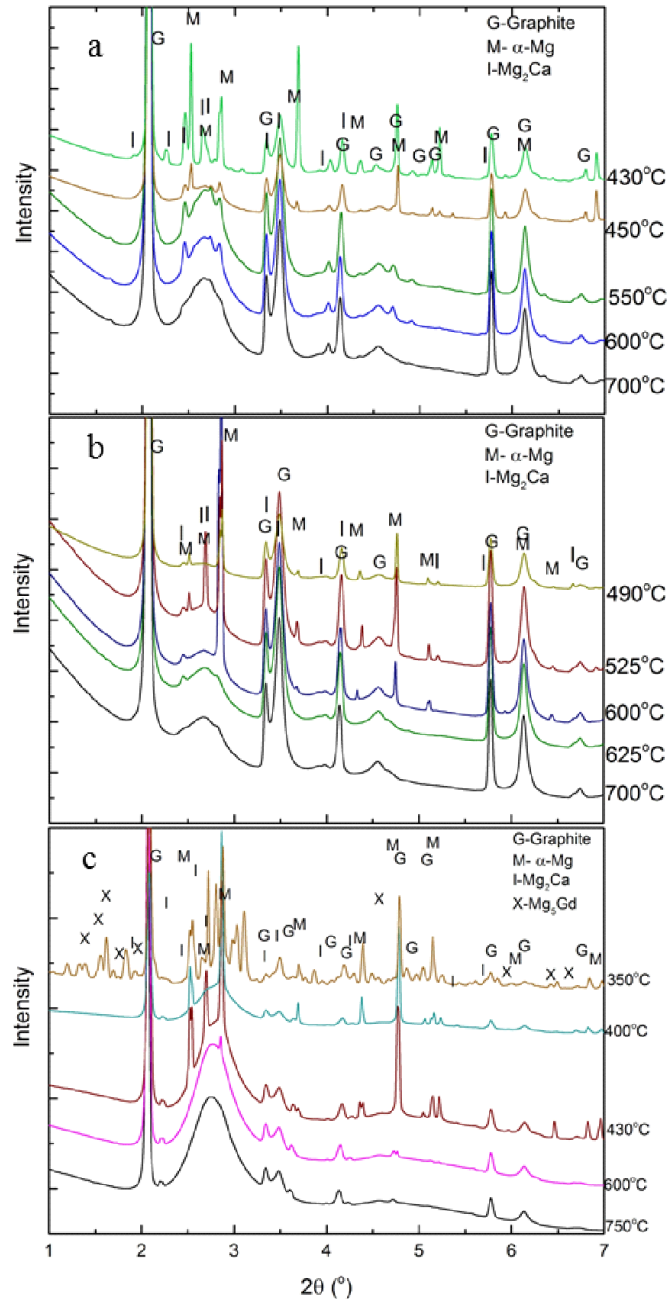

Fig. 2. As in Fig. 1, but for cooking rate of $50 \mathrm{~K} \mathrm{~min}-1$.

decreased significantly. The $\alpha-\mathrm{Mg}$ was first detected at $628 \pm 5,620 \pm 5$, and $620 \pm 5^{\circ} \mathrm{C}$ for $\mathrm{Mg} 10 \mathrm{Ca} 5 \mathrm{Gd}$, Mg10Ca10Gd, and Mg10Ca20Gd alloys, respectively. The $\mathrm{Mg}_{2} \mathrm{Ca}$ phase was detected at $450 \pm 5,498 \pm 5$, and $446 \pm 5{ }^{\circ} \mathrm{C}$ for $\mathrm{Mg} 10 \mathrm{Ca} 5 \mathrm{Gd}, \mathrm{Mg} 10 \mathrm{Ca} 10 \mathrm{Gd}$, and $\mathrm{Mg} 10 \mathrm{Ca} 20 \mathrm{Gd}$, respectively, while $\mathrm{Mg}_{5} \mathrm{Gd}$ was detected at $417^{\circ} \mathrm{C}$ in $\mathrm{Mg} 10 \mathrm{Ca} 20 \mathrm{Gd}$ alloy.

The samples used for in situ investigation of solidification were examined with SEM to observe the solidified microstructures at both cooling rates, Fig. 3. The microstructures of samples solidified at a cooling rate of $5 \mathrm{~K} \mathrm{~min}^{-1}$, Fig. $3 \mathrm{a}-\mathrm{c}$, showed that there is an increase in the amount of intermetallic phases with the increase in $\mathrm{Gd}$ concentration. Mg10Ca5Gd, Fig. 3a, and Mg10Ca10Gd, Fig. 3b, show backscattered electron contrast due to only one intermetallic phase whereas in Mg10Ca20Gd alloy 2 phases could be observed, Fig. 3c. The increase in the cooling rate to $50 \mathrm{~K} \mathrm{~min}^{-1}$ did not show any changes in the contrast due to formation of any new phases, Fig. 3d-f. However, coarsening of the microstructures, especially the intermetallic particles in the 


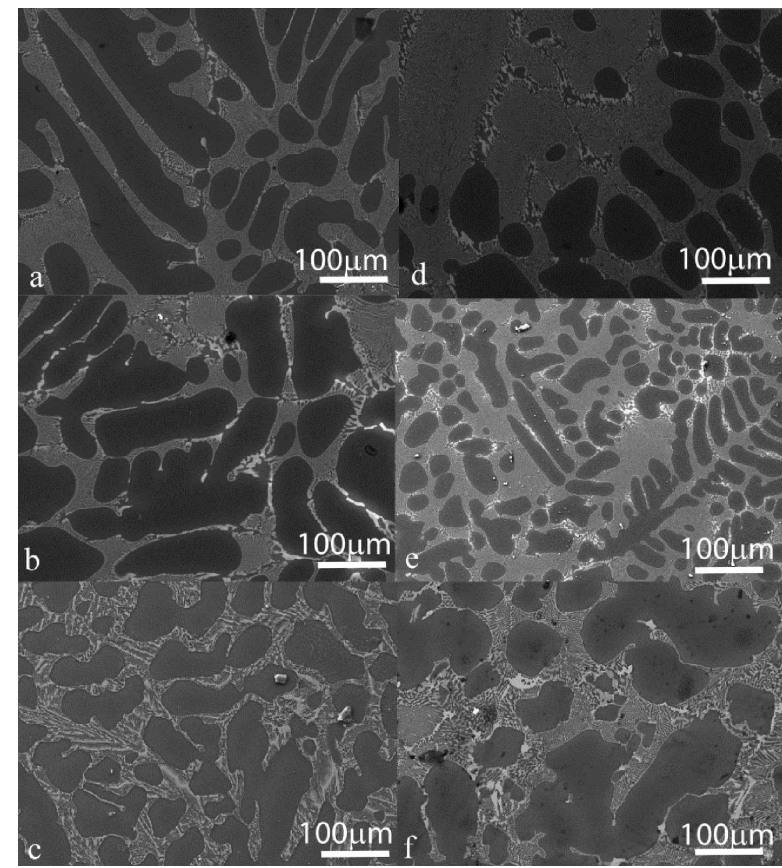

Fig. 3. SEM micrographs showing the final microstructures of the solidified samples with a cooling rate of $(\mathrm{a}-\mathrm{c}) 5 \mathrm{~K} \mathrm{~min}^{-1}$ and $(\mathrm{d}-\mathrm{f}) 50 \mathrm{~K} \mathrm{~min}^{-1}$ for (a, d) Mg10Ca5Gd (b, e) Mg10Ca10Gd and (c, f) Mg10Ca20Gd alloys.

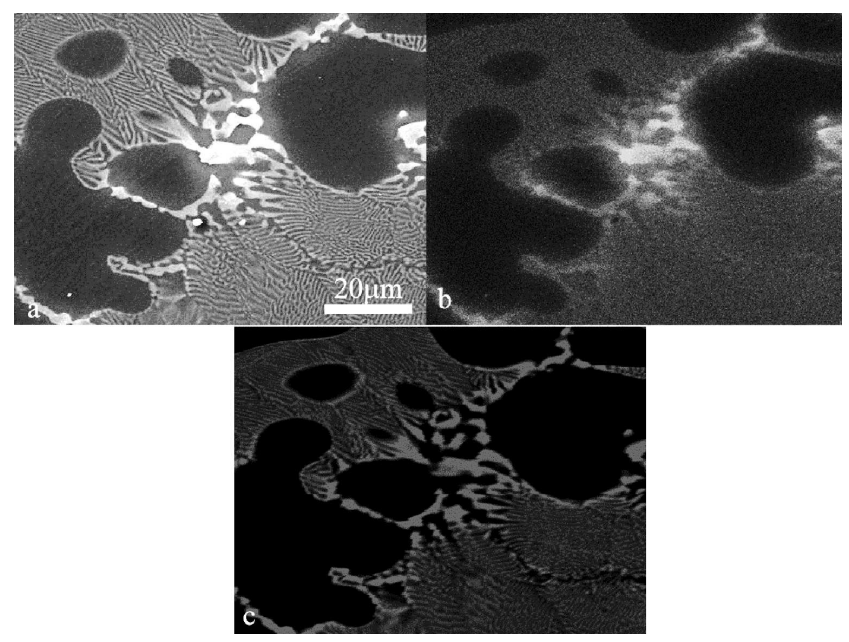

Fig. 4. EDX elemental maps recorded from Mg10Ca10Gd alloy following the in situ investigation during solidification at a cooling rate of $50 \mathrm{~K} \mathrm{~min}^{-1}$ (a) SEM image (b) Gd map and (c) Ca map.

inter-dendritic regions are observed. The Mg10Ca5Gd and Mg10Ca10Gd alloys only contained a single intermetallic phase while the increase in Gd content to $20 \mathrm{wt} \%$ shows the presence of two different intermetallic phases through the microstructure, Fig. 3f.

SEM EDX elemental maps for Mg10Ca10Gd cooled at $50 \mathrm{~K} \mathrm{~min}^{-1}$ are shown in Fig. 4 as typical of those recorded from intermetallic phases. The elemental maps show that there is $\mathrm{Ca}$ and $\mathrm{Gd}$ found in the intermetallic phase observed in the microstructure and that there is some Gd distributed through the magnesium matrix. However, there is no evidence of a second intermetallic phase observed along the inter-dendritic regions. The maps recorded from Mg10Ca10Gd alloys at $5 \mathrm{~K} \mathrm{~min}{ }^{-1}$ and maps recorded from $\mathrm{Mg} 10 \mathrm{Ca} 5 \mathrm{Gd}$ alloys at both cooling rates are comparable with the results presented in Fig. 4.

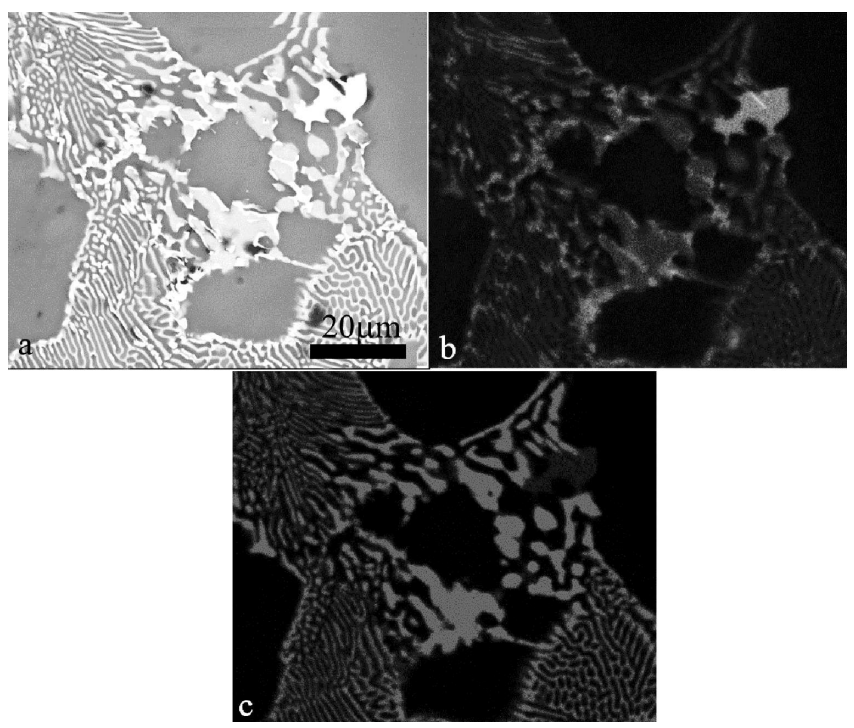

Fig. 5. As in Fig. 4, but for Mg10Ca20Gd.

A typical SEM EDX map recorded from Mg10Ca20Gd alloy cooled at $50 \mathrm{~K} \mathrm{~min}^{-1}$ is shown in Fig. 5. The elemental maps show clearly the presence of two different intermetallic phases. The first phase is similar to that observed in the Mg10Ca10Gd alloy with some Gd soluble in the Ca rich intermetallic phase. The second intermetallic phase is enriched with Gd but there is some Ca dissolution within this intermetallic phase. At a slower cooling rate of $5 \mathrm{~K} \mathrm{~min}^{-1}$ microstructure observed for the Mg10Ca20Gd is similar to that presented here.

\section{Discussion}

The HEXRD line profiles show only the presence of one intermetallic phase in the Mg10Ca5Gd and Mg10Ca10Gd alloys during solidification even though the Scheil solidification calculations predict the presence of two different intermetallic phases, namely $\mathrm{Mg}_{2} \mathrm{Ca}$ and $\mathrm{Mg}_{5} \mathrm{Gd}$ phases. The presence of only one intermetallic phase is also supported by the SEM analysis conducted on the as-solidified samples. There are, however, two intermetallic phases observed in the Mg10Ca20Gd alloys at both cooling rates as predicted with Scheil calculations. The diffraction patterns show that the intermetallic phases observed in Mg10Ca20Gd alloy are $\mathrm{Mg}_{2} \mathrm{Ca}$ and $\mathrm{Mg}_{5} \mathrm{Gd}$ phases.

The start of phase transformation temperatures predicted by the Scheil calculations are compared to those 
measured with HEXRD and generally the temperatures at which $\alpha-\mathrm{Mg}$ phase solidifies are higher from the HEXRD measurement as compared with the values predicted by Scheil calculations, Table II and Table III. The temperature predicted by Scheil calculations for the $\alpha$-Mg phase was $60-80^{\circ} \mathrm{C}$ lower than that measured with HEXRD for a cooling rate of $5 \mathrm{~K} \mathrm{~min}^{-1}$. However, the formation temperature for the $\mathrm{Mg}_{2} \mathrm{Ca}$ phase occurs in the temperature range $515-504{ }^{\circ} \mathrm{C}$ which is comparable with the predicted formation temperature for $\mathrm{Mg}_{2} \mathrm{Ca}$ phase at $513-510^{\circ} \mathrm{C}$ for the alloys investigated at a cooling rate of $5 \mathrm{~K} \mathrm{~min}^{-1}$. The formation temperature of $504^{\circ} \mathrm{C}$ observed for $\mathrm{Mg}_{5} \mathrm{Gd}$ in $\mathrm{Mg} 10 \mathrm{Ca} 20 \mathrm{Gd}$ alloy was comparable with that predicted for $\mathrm{Mg}_{5} \mathrm{Gd}$ with the Scheil calculations at $509^{\circ} \mathrm{C}$.

The increase in the cooling rate to $50 \mathrm{~K} \mathrm{~min}^{-1}$ did not suppress the temperature at which $\alpha$-Mg phase was first observed, but the temperature at which $\mathrm{Mg}_{2} \mathrm{Ca}$ formed was supressed to $\approx 450{ }^{\circ} \mathrm{C}$ for $\mathrm{Mg} 10 \mathrm{Ca} 5 \mathrm{Gd}$ and Mg10Ca20Gd alloys but the suppression was not significant for $\mathrm{Mg} 10 \mathrm{Ca} 10 \mathrm{Gd}$ alloy at $\approx 498^{\circ} \mathrm{C}$, Table III. This is a suppression of $\approx 50^{\circ} \mathrm{C}$ from that predicted with the Scheil calculations. The $\mathrm{Mg}_{5} \mathrm{Gd}$ phase formed at $417^{\circ} \mathrm{C}$ for $\mathrm{Mg} 10 \mathrm{Ca} 20 \mathrm{Gd}$ alloy at a cooling rate of $50 \mathrm{~K} \mathrm{~min}^{-1}$ and is $\approx 90^{\circ} \mathrm{C}$ suppression from that predicted with Scheil calculations.

The ternary phase diagram of the $\mathrm{MgCaGd}$ system is yet to be fully evaluated and some preliminary work was conducted by Fei et al. at $400{ }^{\circ} \mathrm{C}[9]$ on the $\mathrm{Mg}$ rich end of the phase diagram. In the current investigation the ternary phase reported by Fei et al. in their investigations was not observed. Additionally $\mathrm{Mg}_{3} \mathrm{Gd}$ phase observed by Ding et al. [12] during their investigations of Mg1CaxGd alloys $(x=1-3 w t \%)$ was not observed in the current investigation. The Scheil calculations used for the current investigation were predicted by the extension of the three binary systems into the ternary phase field. Thus accurate measurements on the ternary solubilities and the extensions of phases due to solubility of $\mathrm{Gd}$ and $\mathrm{Mg}_{2} \mathrm{Ca}$ and $\mathrm{Ca}$ and $\mathrm{Mg}_{5} \mathrm{Gd}$ phases cannot be accurately predicted. Based on the current solidification studies it is envisaged that the $\mathrm{Mg}_{2} \mathrm{Ca}$ phase has a larger solubility of $\mathrm{Gd}$ and extends into the ternary phase field more than the $\mathrm{Mg}_{5} \mathrm{Gd}$ phase. It is not clear whether this extension is caused by the solubility differences between the two alloying additions in $\mathrm{Mg}$. Gd has a wide solubility range with maximum solid solubility close to $23 \mathrm{wt} \% \mathrm{Gd}$ [8] while $\mathrm{Ca}$ only has a maximum solid-solubility of $1.34 \mathrm{wt} \%$ in $\mathrm{Mg}$ [8]. The content of $\mathrm{Gd}$ in the alloys investigated is below the solubility limit of $\mathrm{Gd}$ and thus in case of 5 and $10 \mathrm{Gd}$ containing alloys the majority of $\mathrm{Gd}$ remains in solution both in $\mathrm{Mg}_{2} \mathrm{Ca}$ intermetallic and the $\alpha-\mathrm{Mg}$ matrix. However, there is a super-saturation of $\mathrm{Gd}$ in Mg10Ca20Gd alloy which causes $\mathrm{Mg}_{5} \mathrm{Gd}$ phase to form.

\section{Conclusions}

In situ investigation of solidification of $\mathrm{Mg} 10 \mathrm{Ca} x \mathrm{Gd}$ $(x=5,10,20)$ showed that the change in cooling rate from 5 to $50 \mathrm{~K} \mathrm{~min}^{-1}$ did not result in changes of the type of intermetallic phases given the composition of the alloy. When the Gd content was less that $20 \mathrm{wt} \%$ only one intermetallic phase was observed and it was found to be $\mathrm{Mg}_{2} \mathrm{Ca}$ phase. In $\mathrm{Mg} 10 \mathrm{Ca} 20 \mathrm{Gd}$ alloy, $\mathrm{Mg}_{5} \mathrm{Gd}$ phase was observed in addition to the $\mathrm{Mg}_{2} \mathrm{Ca}$ phase. The transformation start temperature for $\alpha$ - Mg phase predicted via the Scheil solidification calculations was lower than that observed during solidification while the transformation temperature for $\mathrm{Mg}_{2} \mathrm{Ca}$ and $\mathrm{Mg}_{5} \mathrm{Gd}$ phases observed with a cooling rate of $5 \mathrm{~K} \mathrm{~min}^{-1}$ was similar to those predicted by the Scheil calculations. However, the increase in the cooling rate to $50 \mathrm{~K} \mathrm{~min}^{-1}$ resulted in transformation start temperatures for observing $\mathrm{Mg}_{2} \mathrm{Ca}$ and $\mathrm{Mg}_{5} \mathrm{Gd}$ phases to lower temperatures than those predicted by the Scheil calculations.

\section{Acknowledgments}

The authors acknowledge the Deutsches ElektronenSynchrotron for the provision of synchrotron radiation facilities in the framework of the proposal I-20130434I20120627.

\section{References}

[1] N. Hort, Y. Huang, D. Fechner, M. Störmer, C. Blawert, F. Witte, C. Vogt, H. Drücker, R. Willumeit, K.U. Kainer, F. Feyerabend, Acta Biomater. 6, 1714 (2010).

[2] L. Yang, Y. Huang, F. Feyerabend, R. Willumeit, C. Mendis, K.U. Kainer, N. Hort, Acta Biomater. 9, 8499 (2013).

[3] M. Yamasaki, T. Anan, S. Yoshimoto, Y. Kawamura, Scr. Mater. 53, 799 (2005).

[4] H. Yokobayashi, K. Kishida, H. Inui, M. Yamasaki, Y. Kawamura, Acta Mater. 59, 7287 (2011).

[5] J.F. Nie, X. Gao, S.M. Zhu, Scr. Mater. 53, 1049 (2005).

[6] K. Yamada, H. Hoshikawa, S. Maki, T. Ozaki, Y. Kuroki, S. Kamado, Y. Kojima, Scr. Mater. 61, 636 (2009).

[7] T. Laser, Ch. Hartig, M.R. Nürnberg, D. Letzig, R. Bormann, Acta Mater. 56, 2791 (2008).

[8] A.A. Nayeb-Hashemi, J.B. Clark, Phase Diagrams of Binary Magnesium Alloys, ASM International, Metal Park 1988.

[9] H.-J. Fei, G.-J. Xu, L.-B. Liu, H. Bo, L.-J. Zeng, C.P. Chen, Trans. Nonferrous Met. Soc. China 23, 881 (2013).

[10] S.M. He, X. Zeng, L. Peng, X. Guo, J. Chang, W. Ding, Mater. Sci. Forum 546-549, 101 (2007).

[11] Pearson's - Crystal Structure Database for Inorganic Compounds (on CD-ROM), Eds. P. Villars, K. Cenzual, Release 2012/13.

[12] Y.-T. Ding, Z. Zhao, D.-X. Liu, Y. Hu, Lanzhou Ligong Daxue Xuebao 39, 1 (2013). 